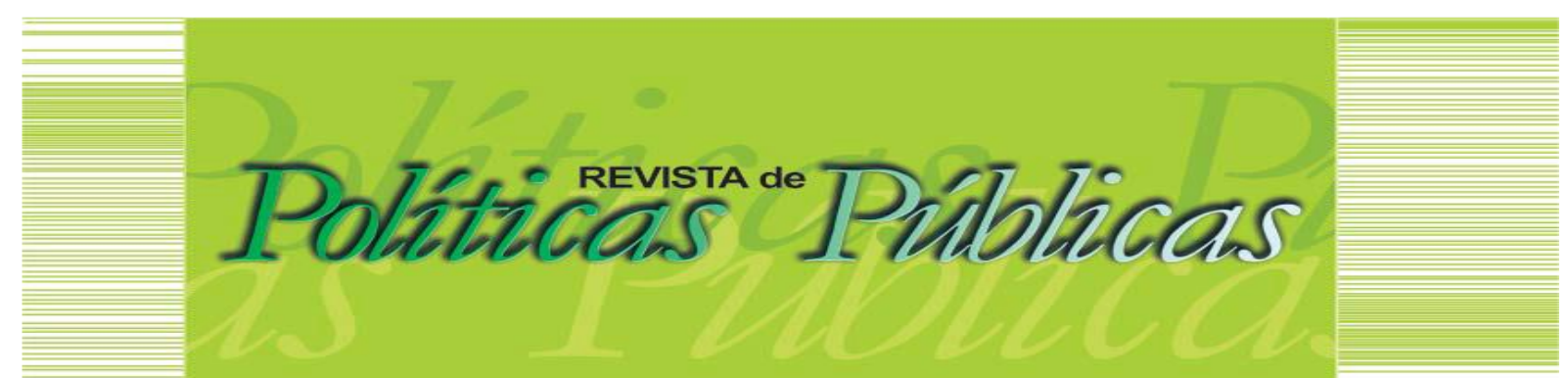

\title{
SISTEMAS DE PROTEÇÃO SOCIAL LATINO-AMERICANOS E RESPOSTAS À PANDEMIA DE COVID-19: Argentina, Brasil e México
}

\author{
Mônica de Castro Maia Senna ${ }^{1}$ \\ Aline Souto Maior Ferreira ${ }^{2}$ \\ Valentina Sofia Suarez Baldo ${ }^{3}$
}

\begin{abstract}
Resumo
O artigo analisa como sistemas de proteção social na América Latina têm respondido à grave situação social decorrente da pandemia de COVID-19. Pautado em estudo exploratório, o artigo toma como foco as experiências da Argentina, Brasil e México. A perspectiva de análise considera que as respostas produzidas por esses três casos às demandas sociais postas pela pandemia decorrem da interseção entre o legado prévio e estrutura institucional dos sistemas de proteção social existentes em cada país, a orientação política dos governos em exercício e a dinâmica social e política diante do contexto da crise sanitária. Verifica que nos três países, a despeito de medidas protetivas de maior ou menor abrangência e magnitude, que reforçam a proteção social existente ou introduzem novos mecanismos - todos eles temporários - a crise social própria às formações sociais latino-americanas se agravou.
\end{abstract}

Palavras-chave: Proteção social. COVID-19. Brasil. México. Argentina

\section{LATIN AMERICAN SOCIAL PROTECTION SYSTEMS AND RESPONSES TO THE COVID-19 PANDEMIC: Argentina, Brazil and Mexico}

\begin{abstract}
The article analyses how social protection systems in Latina America have responded to the serious social situation caused by the COVID-19 pandemic. Guided by an exploratory study, the paper focuses on the experiences of Argentina, Brazil and Mexico. The analysis considers that the responses produced by the three cases results from the intersection between the institutional structure's previous legacy of the social protection systems existing in each country, the political orientation of the governments in exercise and the social and political dynamics in the sanitary crisis context. It seems that, despite protective measures of greater or lesser scope and magnitude, which either reinforce the existing social protections or introduce new mechanisms - all of them temporary - the social crisis specific to Latin American social formations has worsened in the countries studied.
\end{abstract}

Keywords: Social protection. COVID-19. Brazil. México. Argentina

Artigo recebido em: 21/12/2020 Aprovado em: 20/05/2021

DOI: http://dx.doi.org/10.18764/2178-2865.v25n1p263-284

\footnotetext{
1 Assistente Social. Doutora em Ciências - Saúde Pública pela Escola Nacional de Saúde Pública (ENSP)/ FIOCRUZ. Professora Titular do Quadro Permanente do Programa de Estudos Pós-graduados em Política Social (PGPS) e da Escola de Serviço Social (ESS) da Universidade Federal Fluminense (UFF). Pesquisadora CNPq. E-mail: monica_senna@id.uff.br ${ }^{2}$ Assistente Social. Doutora em Ciências Sociais pela Universidad de Guanajuato (México). Assistente Social do Instituto Nacional de Cardiologia (INC) do Ministério da Saúde. E-mail: aline.soutomaior@yahoo.com.br

${ }^{3}$ Assistente Social. Doutora em Política Social pela Universidade Federal Fluminense. Bolsista do Programa Nacional de Pós-Doutorado (PNPD) no Instituto de Medicina Social (IMS) da Universidade do Estado do Rio de Janeiro (UERJ). Email: valentinasb@hotmail.com
} 


\section{INTRODUÇÃO}

Ao final de 2019, o mundo assistia ao início do que seria reconhecido pela Organização Mundial de Saúde (OMS) como a pandemia de COVID-19. Em poucos meses e em velocidade avassaladora, a pandemia atingiu os cinco continentes do planeta (exceção da Antártida), deixando milhares de mortes, agravamento da crise econômica mundial, aumento da pobreza e aprofundamento das desigualdades sociais. Nesse cenário turbulento e de incertezas, ganha centralidade 0 debate sobre as políticas sociais e a capacidade de 0 Estado garantir proteção social. Além das medidas para evitar a propagação da pandemia e prover tratamento oportuno e eficaz aos acometidos, é fundamental assegurar condições de bem-estar social em suas múltiplas dimensões, sobretudo para os afetados pela perda de emprego e renda.

Esse debate é relevante na América Latina, que concentra países com as piores desigualdades sociais do mundo, prevalência de altos níveis de informalidade laboral e baixa capacidade de incorporação das demandas sociais pelo Estado (FLEURY, 2017). Ao mesmo tempo, como sublinha Laurell (1998), os regimes de bem-estar latino-americanos têm se afastado de padrões de serviços universais e equitativos, tendo suas origens e desenvolvimento associados à concessão de privilégios corporativos dirigidos a trabalhadores formais com elevados graus de exclusão. Barba Solano (2007) enfatiza que, com raras exceções, as experiências latino-americanas não têm contado com democracias duradouras, não garantem todos os direitos civis e políticos ou a universalização dos direitos sociais para o conjunto da população e tampouco atingem os niveis de assalariamento dos países centrais.

O presente artigo analisa como sistemas de proteção social na América Latina têm respondido à grave situação social decorrente da pandemia de COVID-19. Enfatiza-se aqui a análise sobre as respostas governamentais no campo da saúde e da proteção ao emprego e renda. Entendese, com base em Jaccoud (2009: p. 58), a proteção social como "um conjunto de iniciativas públicas ou estatalmente reguladas para a provisão de serviços e benefícios sociais visando enfrentar situações de risco social ou privações sociais". O estudo foca nas experiências da Argentina, Brasil e México, países considerados paradigmáticos no continente em função da estreita associação entre industrialização e montagem dos sistemas de proteção social a partir do modelo de substituição de importações iniciado nos anos 1930. Não obstante suas singularidades, os três se destacam na região e na geopolítica mundial por sua importância em termos demográficos, econômicos e políticos, contrastando elevados níveis de riqueza com estruturas sociais profundamente desiguais. 


\section{SISTEMAS DE PROTEÇÃO SOCIAL LATINO-AMERICANOS E RESPOSTAS À PANDEMIA DE COVID-19: Argentina, Brasil e México}

Longe de tomar as experiências desses países como homogêneas, a perspectiva que orienta 0 artigo considera que as respostas produzidas pelos mesmos às demandas sociais postas pela pandemia decorrem da interseção entre legado prévio e estrutura institucional dos sistemas de proteção social existentes em cada país, a orientação política dos governos em exercício e a dinâmica social e política diante do contexto da crise sanitária. É a busca de aspectos comuns, mas também singulares, que orienta a análise, a qual se pauta pela perspectiva de estudos de casos múltiplos (YIN, 2001), sem pretensão de proceder a um estudo comparativo entre essas experiências.

Um traço comum aos sistemas de proteção social na região é a prevalência de modelos segmentados, decorrentes, em parte, do perfil de seguro social adotado na maioria dos países, restrito a algumas categorias de trabalhadores urbanos do mercado formal de trabalho, e, portanto, com forte caráter seletivo, cobertura limitada, baixa densidade contributiva, heterogeneidade dos benefícios e assimetrias para habilitação (COBO et al., 2010).

Filgueira (2015) examina as formas assumidas pela política social nos países latinoamericanos, relacionando-as às modalidades de acumulação econômica, à estrutura social e às dinâmicas políticas de cada período histórico. 0 autor identifica quatro grandes momentos de conformação dos sistemas de proteção social latino-americanos, vinculados às etapas de desenvolvimento econômico. O Estado social minimalista corresponde ao período entre 1870 a 1930, em que a maioria dos países desenvolveu um modelo agrário exportador, ao mesmo tempo em que ampliava a atuação estatal na promoção de medidas sanitárias, na expansão da educação laica e na constituição dos primeiros sistemas previdenciários.

O Estado social de base contributiva corresponde a uma nova etapa de desenvolvimento entre os anos 1930 a 1980, quando parte dos países da região instituiu seus regimes de proteção social relacionados às especificidades do capitalismo periférico e seu correlato modelo de industrialização por substituição de importações. A característica mais comum do período foi a constituição de um padrão corporativo para aos setores urbanos formalmente empregados, com consequente estratificação e exclusão de amplas camadas da população, elementos marcantes dos sistemas de proteção social dos países abordados.

A crise do capital nos anos 1970 e o esgotamento do modelo de substituição de importações impulsionaram o terceiro momento identificado por Filgueira (2015) como Estado Social Refratário, em que reformas neoliberais ganharam força e induziram mudanças nos sistemas de proteção social de diversos países, por meio de ajustes estruturais e do recuo do Estado. Na primeira década e meia do século XXI, o autor identifica um momento expansivo do Estado social associado a um modelo neodesenvolvimentista, quando avançou o gasto social na região; vários países implementaram políticas de enfrentamento da pobreza, influenciados sobretudo pelos programas de 
transferência condicionada de renda brasileiro e mexicano; houve maior intervenção do estado na economia; e buscou-se maior integração entre os países da região. Essas tendências se aplicaram em maior ou menor grau a diversos países e embora alguns tenham vivenciado a insurreição de importantes movimentos sociais que denunciaram a expropriação, exploração e empobrecimento da população, não lograram levar ao poder político grupos de orientação mais progressista, como é o caso do México.

Após esse período, um quinto momento passou a se delinear na região, quando forças conservadoras alinhadas à agenda neoliberal ganharam espaço no continente, sobretudo a partir de 2013, inclusive recorrendo a golpes políticos. Embora países como Argentina e mais recentemente Bolívia tenham retomado uma direção progressista, a disputa política por projetos societários distintos encontra-se em aberto.

Apesar dos importantes avanços nos indicadores sociais da região na primeira década dos anos 2000 (reitera-se a exceção do México), o recrudescimento da crise econômica e a adoção de políticas de austeridade e corte dos gastos sociais levaram novamente o continente mais desigual do mundo a vivenciar o aumento da pobreza, da fome, das iniquidades sociais e do desemprego. É nesse quadro que irrompe a pandemia no continente, aprofundando a já gravíssima crise econômica e as desigualdades sociais da região, o que coloca a exigência de medidas protetivas levadas a cabo pelo Estado.

0 presente artigo se estrutura em três seções, além dessa introdução e das considerações finais. Na primeira seção, são abordadas as características centrais dos sistemas de proteção social dos três países, considerando tanto elementos estruturais quanto aspectos mais conjunturais relacionados à condução política dos governos recentes. A segunda seção examina como os sistemas de saúde desses países estão estruturados e de que forma eles têm respondido à pandemia, enquanto a terceira seção se dedica à análise das principais iniciativas governamentais desses países para garantir a proteção social diante do dramático cenário social agravado pela pandemia.

\section{SISTEMAS DE PROTEÇÃO SOCIAL NA REGIÃO: características centrais e reformas recentes}

Em meio à crise econômica e política no Brasil, após um pleito muito polarizado foi eleito Jair Bolsonaro (sem partido) que assumiu em janeiro de 2019. Apoiado por segmentos que tramaram o Golpe de 2016 que levou ao impeachment da presidente Dilma Rousseff (Partido dos Trabalhadores, 2011-2016), pela cúpula militar e por setores religiosos ultraconservadores, o presidente adotou uma pauta econômica ultraliberal, autoritária no trato dos conflitos sociais e altamente conservadora no 
plano político. Intensificou o enxugamento do Estado, com reformas estruturais como a da Previdência, a Tributária, a Administrativa e a do Pacto Federativo, cortes nos gastos públicos, desoneração dos ganhos de capital e privatização. Seu governo manteve as severíssimas medidas do governo Michel Temer (MDB, 2016-2018), com destaque para a Emenda Constitucional $n^{\circ}$ 95/2016 (EC n 95/2016), que congela o teto dos gastos públicos por 20 anos, adotando um modelo de austeridade fiscal, talvez 0 mais agressivo do mundo. Essas medidas afetaram diretamente o tripé da Seguridade Social brasileira, instituída na Constituição de Federal de 1988, que é composto por uma política de Saúde universal e gratuita, pela Assistência Social, alçada então pela primeira vez à categoria de direito social para todos que dela necessitarem, e Previdência Social, contributiva, porém com corresponsabilidade de financiamento público e patronal. Também merece destaque a Reforma Trabalhista, que ampliou a flexibilização, generalizando a terceirização, desonerou as obrigações patronais e atacou os direitos trabalhistas no Brasil, retrocedendo a uma condição de desproteção anterior à Era Vargas. Toda essa ofensiva gerou desemprego (13 milhões em julho de 2019), atroz aumento da informalidade (taxa média no ano de 2019 de 41,1\%, com mais 38 milhões de trabalhadores informais segundo a PNAD Contínua) e um crescimento desprezível do PIB nacional (1,1\% em 2019), associados à pior taxa de desindustrialização da história do país.

Os efeitos sociais dessas medidas se fizeram sentir. De acordo com o IBGE, houve aumento da fome e insegurança alimentar, atingindo 10,3 milhões de brasileiros em 2018; acirramento da pobreza, que passou de 52,8 para 54,8 milhões de pessoas entre 2016 e 2017 e das desigualdades sociais (IBGE, 2019). Segundo o Ministério da Saúde, até a mortalidade infantil recrudesceu: em 2016 a taxa foi de 14 mortes/ mil habitantes, fato inédito desde os anos 1990 (BRASIL, 2019).

Ao mesmo tempo, houve significativo esvaziamento das políticas de proteção social. Os serviços da Assistência Social, e seus principais benefícios, o Programa Bolsa Família e Benefício de Prestação Continuada (BPC) enfrentaram cortes orçamentários. Os valores dos benefícios não foram reajustados, novas concessões foram freadas e uma fiscalização mais rígida levou ao corte de 1,2 milhões de famílias em 2019. Também em 2019, pela primeira o BPC apresentou queda no número de beneficiários (BBC News, 2020).

Já na Argentina, onde os direitos sociais estiveram sempre associados ao trabalho assalariado (LANZARA, 2016), a proteção social acaba sendo fundamentada na tutela jurídica do contrato de trabalho, mas se constitui como um sistema abrangente, já que mais de $90 \%$ das pessoas de mais de 65 anos recebem algum benefício previdenciário (CETRÁNGOLO; GRUSHKA, 2020). No entanto, o sistema de seguro social contributivo é bastante fragmentado (ANDRENACCI et al, 2004) e o problema estrutural que se apresenta é a combinação de um sistema de proteção social estreitamente vinculado ao emprego formal, com altos índices de trabalho informal, que em fins de 
2018 era de 49,3\% da população ocupada (DONZA, 2019), acompanhado de desemprego de 10,4\% (INDEC, 2020a) e de indicadores de pobreza e miséria de 35,4\% e 7,7\% (INDEC, 2020b). A informalidade termina por desproteger o trabalhador duplamente: em relação à renda, pois os trabalhadores informais têm pior remuneração, e pelas restrições no acesso a direitos trabalhistas e previdenciários.

A partir de 2009 foi instituído o Programa Asignación Universal por Hijo(AUH), principal política de assistência social, que embora se configure como Transferência Condicionada de Renda, rompeu com o princípio contributivo da proteção social ao ser incluído na Previdência Social, no regime de prestações familiares.

O presidente Alberto Fernández (Frente de Todos), ao assumir em dezembro de 2019, herdou uma situação catastrófica de Mauricio Macri (Cambiemos, 2015-2019): país em recessão, endividado, desindustrializado, com o valor patrimonial das empresas destruído e altos índices de inflação e pobreza. A orientação liberal do governo Macri havia extinguido o Ministério de Saúde, rebaixando-o ao patamar de secretaria em 2018. (ZAIAT, 2019). Desde o princípio, Fernández mostrou a intenção de reverter a política anterior, com medidas de orientação keynesiana, políticas protecionistas e de reativação do mercado interno, outorgando ao Estado um papel intervencionista regulador (BRODA, 2020). Entre elas o endurecimento do imposto à exportação de grãos; a criação de imposto à compra de dólares; o congelamento dos preços da energia elétrica e gás por seis meses; a redução e congelamento dos preços de medicamentos; o congelamento do preço dos transportes de passageiros e dos pedágios em estradas nacionais; além de aumento salarial para os trabalhadores formais do setor privado e um auxílio para os do setor público nacional.

O México apresenta algumas peculiaridades. Mesmo durante o período de maiores avanços sociais na América Latina, a pobreza esteve insistentemente ao redor de 50\% da população, ainda que o país tenha renda per capita mediana alta (BANCO MUNDIAL, 2015). Ao longo dos últimos 30 anos, o país enfrentou falta de dinamismo econômico, volatilidade financeira e quase permanente recessão, enquanto a "abertura comercial e financeira" tornou a economia mexicana mais vulnerável e dependente dos Estados Unidos (DAMIÁN, 2011).

$\mathrm{O}$ país chegou à segunda década do século XXI com uma política social altamente segmentada, que não alcançou combater a desigualdade social, característica presente até nas políticas de caráter mais universal, como a educação e a saúde. No que se refere à proteção social não contributiva, essa não é um direito social garantido. A população que não tem acesso à Seguridade Social por meio de filiação ao trabalho formal é atendida por programas sociais de iniciativa do governo e não uma política de Estado com objetivos, parâmetros, serviços, recursos, público, regulamentados 
constitucionalmente (SOUTO MAIOR 2015). Assim, a população mais vulnerável do país depende da oferta de programas sociais do governo em turno.

Até 2018 o Programa de Transferência de Renda Prospera, que passou por mudanças de nomenclatura nas trocas de governo, e era o principal programa social do México. Apesar das suas limitações, entre elas a não cobertura da totalidade da população pobre e os valores insuficientes, as várias avaliações do programa demonstraram a importância do mesmo para atenção a necessidades básicas das famílias e aumento da trajetória educativa; destaca-se o esforço do CONEVAL (Consejo Nacional de Evaluación de la Política de Desarrollo Social) em promover e publicizar avaliações da transferência de renda no país.

Ao assumir a presidência do México em dezembro de 2018, Andrés Manuel López Obrador (Morena), que vinha se destacando com um discurso de centro-esquerda, não interrompeu a direção econômica anterior, tendo inclusive assinado novo acordo comercial com Estados Unidos e Canadá. No entanto, efetuou mudanças significativas no que se refere às políticas sociais, implementando uma série de programas e investimentos em infraestruturacom o objetivo de enfrentar um dramático quadro social. Dados apontam que, embora em maio de 2019 a desocupação estivesse na casa de 3,5\% do total de ocupados no país, cerca de 51,8\% eram informais (INEGI, 2020) e a pobreza seguia em alto patamar, atingindo $44,5 \%$ da população (CONEVAL, 2020b).

Cabe destaque o fim do Programa Prospera e sua substituição pelo programa de auxílios econômicos exclusivamente para a escolarização por meio de bolsas. Outra mudança foi a ampliação da proteção social aos idosos pela implementação do Programa Pensión para el Bienestar de los Adultos Mayores (MÉXICO, 2020b), dirigido a todos os maiores de 68 anos (65 se moradores de comunidades indígenas). Trata-se de um alargamento importante, pois o quantitativo de idosos com direito à pensão contributiva é baixo e a pandemia intensificou a vulnerabilidade desse grupo.

\section{AS RESPOSTAS DOS SISTEMAS DE SAÚDE}

O primeiro caso confirmado de COVID-19 na América Latina foi registrado no Brasil em 26 de fevereiro de 2020, seguido, dois dias depois, pelo primeiro registro no México. Na Argentina, a primeira ocorrência do novo coronavírus surgiu em 03 de março, quando mais outros dois países da região (Equador e República Dominicana) já haviam notificado seus primeiros casos. Em todos esses países, os casos iniciais eram procedentes da Europa, então o epicentro da pandemia. Desde então 0 Brasil contabilizou, até 18 de dezembro de 2020, 7.163.912 casos confirmados e 184.827 óbitos, ocupando a terceira posição no ranking global de número de casos e a segunda em número de mortes. $\mathrm{Na}$ Argentina, o número de casos chegou ao total de 1.524.372 casos, com 41.534 óbitos no mesmo 
período, o que corresponde ao décimo e décimo primeiro lugares respectivamente entre os países do mundo, enquanto no México foram confirmados 1.289 .298 casos e 116.487 óbitos, conferindo-lhe a décima terceira posição em número absoluto de casos e a quarta em mortes (JOHNS HOPKINS, 2020).

Embora no início a pandemia tenha atingido os estratos médios e altos, ela logo se ampliou para as camadas mais pobres da população, expressando a determinação social do processo saúde-doença e ressaltando as profundas desigualdades sociais que marcam os países latinoamericanos. Na Argentina, a maioria dos casos concentrou-se na capital e seu entorno metropolitano, iniciando pelos bairros nobres da região norte de Buenos Aires e logo atingindo as áreas mais pobres do centro sul da capital portenha e as chamadas villas miséria (GALINDO; ARROYO, 2020). A região concentra cerca de 15 milhões de pessoas, quase um terço da população nacional. Apenas mais recentemente é que a pandemia se propagou pelo interior do país. Também no México os primeiros casos registrados localizavam-se nos bairros mais ricos da capital, mas a pandemia logo avançou para as áreas mais pobres e densamente povoadas da região metropolitana do Vale do México, com 60 municípios e 22 milhões de habitantes. No Brasil não tardou que a pandemia avançasse para as favelas e áreas periféricas dos grandes centros urbanos do país, atingindo principalmente a população negra e mais pobre dessas localidades (SANTOS et al., 2020). A falta ou insuficiência de saneamento básico, as precárias condições de moradia e a impossibilidade de ficar em casa em função das atividades laborativas e de geração de renda, sobretudo para os trabalhadores do setor informal, aliadas às dificuldades de acesso a serviços de saúde, são fatores que aprofundam a vulnerabilidade dos segmentos sociais mais pobres à incidência e mortalidade por COVID-19.

Os países adotaram um conjunto de medidas para conter a expansão da pandemia, com resultados diversos. Na Argentina, o governo federal assumiu uma postura ativa, decretando isolamento social obrigatório já a partir de março, quando ainda registrava um pequeno número de casos. Foram fechadas escolas e universidades e proibidas atividades que promovessem aglomeração de pessoas. Os voos domésticos e internacionais foram suspensos, as fronteiras fechadas, o uso de transporte público e o comércio restringidos e a circulação só foi permitida para comprar alimentos ou medicamentos, sendo necessária autorização até para exercer atividades liberadas (SUÁREZ BALDO; MATTOS, 2020). O controle da circulação contou com ampliação do policiamento nas ruas e a violação do isolamento poderia resultar em detenção por ameaça à saúde pública.

A adoção dessas restrições foi justificada pela necessidade de preparar o sistema de saúde para atender às demandas relacionadas à pandemia e evitar um possível colapso. 0 governo federal investiu em reformas de unidades de saúde, construção de hospitais modulares e aumento da quantidade de leitos comuns e de UTI, compra de respiradores e insumos tecnológicos e contratação e 
treinamento de profissionais de saúde. Foi instituído um Plano de Resposta Integrada ao COVID-19, com bases científicas e em consonância com as diretrizes da OMS. Implantou-se o programa Detectar para testagem e rastreabilidade, de caráter focalizado. Outras ações governamentais incluíram campanhas educativas e de informação à população, além de tornar obrigatório o uso de máscaras.

Essas medidas foram bem aceitas pela população e contaram com a adesão dos governadores das províncias, mesmo os de oposição ao governo federal. Até setembro de 2020 o país possuía um dos menores números de casos do mundo (JOHN HOPKINS, 2020). Ao contrário de países como o Brasil, a pandemia na Argentina não apresentou pico inicial e seguiu crescimento lento e constante, demonstrando o sucesso das medidas adotadas.

No entanto, a extensão do lockdown, um dos mais severos e prolongados do mundo, passou a gerar insatisfação da população e rejeição dos governos provinciais de oposição às medidas do governo federal, sobretudo em face das consequências econômicas. Aos poucos, o governo foi afrouxando as medidas e autorizando os municípios a decidir sobre atividades econômicas e sociais, conforme o monitoramento da pandemia. Com a flexibilização, o número de casos e de óbitos no país aumentou de modo considerável, sobretudo no interior. O governo federal retomou restrições em termos de funcionamento do comércio e controle da circulação entre províncias, com relativo sucesso, já que o número de casos e de óbitos tornou a cair (COLOMBO, 2020).

No Brasil, estados e municípios têm protagonizado o enfrentamento da pandemia, promovendo medidas de restrição da circulação, suspensão de aulas e fechamento de escolas, de estabelecimentos comerciais e proibição de atividades com aglomeração, além de tornar obrigatório o uso de máscara nas ruas e lugares públicos. Em algumas localidades foram adotadas estratégias de lockdown, mas com grau de adesão variável e tendencialmente baixo por parte da população e dos setores econômicos. Alguns estados e municípios assumiram a realização de testes diagnósticos, embora restritos a casos suspeitos. Também partiram de alguns deles investimentos na contratação de pessoal da saúde, reforma de hospitais, ampliação de leitos, inclusive de UTI, construção de hospitais de campanha e contratação de leitos na rede privados, dentre outras medidas.

Já a postura do governo federal tem sido omissa e um grande entrave ao combate ao COVID-19. Embora contando com a existência prévia de uma considerável estrutura para repostas a emergências em saúde pública (HENRIQUES; VASCONCELOS, 2020), o Ministério da Saúde não apresentou nenhum plano ou diretriz nacional para enfrentar a pandemia. Houve esvaziamento do Ministério da Saúde em sua capacidade de coordenação, e transferência do Centro de Coordenação das Operações do Comitê de Crise da Covid-19 para a Casa Civil (HENRIQUES; VASCONCELOS, 2020). Além disso, durante o período de agravamento da pandemia, assistiu-se a duas trocas de ministros e a pasta chegou a ficar meses sem um titular. A crescente militarização do Ministério da 
Saúde e a suspensão da divulgação diária de dados são outros indícios da pouca importância dada pelo governo federal a essa grave emergência em saúde pública. As secretarias estaduais de saúde passaram a produzir informações diárias, de forma independente do governo federal, e a divulgá-las por meio de um consórcio formado pelos principais veículos de comunicação do país.

0 presidente tem minimizado a gravidade da pandemia, insistido em tratamentos sem comprovação científica e seu negacionismo acompanha intensa polarização política, com a oposição a governadores e prefeitos que adotaram medidas de isolamento social, imputando a eles a responsabilidade pela crise econômica agravada pela pandemia. Essa postura contribui para a baixa adesão da população às medidas de isolamento social. Estudo inédito da Universidade Federal do Rio de Janeiro (UFRJ) realizado em parceria como IRD (Instituto Francês de Pesquisa e Desenvolvimento) aponta que, nas cidades onde o presidente tem mais apoio, os números da pandemia tendem a ser piores (VALOR ECONÔMICO, 2020).

Esse conjunto de aspectos levou o Brasil a ser internacionalmente reconhecido como um dos piores exemplos de governança da crise provocada pela pandemia. As curvas de número de casos e de óbitos seguem em patamares elevados, chegando a todos os estados e aos mais de 5.500 municípios do país. Após ligeira queda registrada em outubro, que motivou afrouxamento de medidas restritivas, nota-se novamente um aumento de casos e óbitos em quase todo o país.

Também no México, foram adotadas medidas restritivas de isolamento social, com suspensão de aulas e atividades econômicas consideradas não essenciais, fechamento de fronteiras e proibição da livre circulação de pessoas e veículos. As primeiras declarações do Presidente tenderam a minimizar a gravidade da pandemia, mas sua rápida propagação mudou esse cenário e já no dia 30 de março de 2020 o governo federal decretou estado de emergência sanitária, o que permitiu à Secretaria de Saúde ditar as ações para atender à emergência e orientar os setores do governo no sentido de proteger empresas e trabalhadores, garantir o fornecimento de alimentos à população, entre outras medidas protetivas.

Durante dois meses iniciais, o governo federal implantou a Jornada Nacional de Sana Distancia, que significou o período mais duro de restrições, ainda que deixando a decisão por medidas mais específicas de quarentena a cargo dos estados e municípios. Após esse período foi estabelecida uma agenda de Nueva Normalidad, que determina o funcionamento de serviços e instituições com base num sistema de semáforos, que vai do vermelho (mais restrito), passando pelo laranja, amarelo e por último verde (sem restrições), de acordo com a incidência de casos e óbitos nas regiões. Essa agenda exige o esforço de monitoramento da pandemia em nível nacional. As classificações são periódicas e abaixo da sinalização vermelha é permitido o funcionamento da maior parte das instituições, à exceção da atividade escolar tradicional, essa permitida somente com sinalização verde 
(MÉXICO, 2020d). A Secretaria de Saúde publiciza informes diários sobre a situação da pandemia no país e mantém os dados disponíveis em plataformas digitais. Em 16 de dezembro de 2020, a informação era de que $21 \%$ do total de casos se concentravam na Cidade do México (MÉXICO, 2020e).

Foram mantidas as principais orientações quanto à permanência em casa das pessoas consideradas grupo de risco, manutenção da distância de 1,5 metros fora de casa, utilização de máscaras e abolição de cumprimentos. Mas os números de casos e óbitos por COVID-19 não pararam de crescer no país e no mês de novembro acendeu o sinal vermelho diante de uma situação alarmante (PRENSA LATINA, 2020). O governo federal decidiu endurecer as medidas restritivas; no entanto, conter a propagação da COVID-19 é um enorme desafio num país que está buscando ampliar sua cobertura de saúde e cuja população apresenta altíssimos índices de pobreza.

De acordo com dados da Universidade John Hopkins (2020), a letalidade por COVID-19 no México era a maior do mundo, alcançando uma taxa de 9\% em 16 de dezembro de 2020, bem acima do segundo colocado, o Irã (4,7\%), da média mundial (cerca de $2 \%$ ), da Argentina $(2,7 \%)$ e do Brasil (2,6\%). No estado de Sinaloa, a taxa de letalidade chegava a $16,04 \%$ na mesma data. No entanto, há que se considerar que o país não adotou uma política de testagem massiva, o que tende a superdimensionar a taxa de letalidade, em função da subnotificação de casos, aspecto esse também ponderado pela OMS. Por outro lado, como afirma Puga (2020), a decisão de não realizar provas massivas colide com o desejo da população de ter maior certeza a respeito dos reais índices de incidência da pandemia no país.

Os três países aqui estudados contam com sistemas de saúde de abrangência nacional e estruturados em bases federativas, o que significa dizer que os entes subnacionais possuem relativa autonomia para tomar decisões e gerir as ações de saúde em seu território, mas sem prescindir do papel coordenador da autoridade central. Entretanto, a segmentação e a fragmentação são traços dos sistemas dos três países, apesar de suas especificidades.

Na Argentina e no México, a oferta da proteção em saúde é majoritariamente vinculada à afiliação dos trabalhadores formais e seus dependentes ao seguro social. Isso é particularmente preocupante diante da grande parcela da população inserida no mercado informal de trabalho. $\mathrm{Na}$ Argentina, o sistema de saúde apresenta diferenças de coberturas, fontes de financiamento, regimes e órgãos de controle e fiscalização. $O$ mesmo é composto por três grandes subsistemas, sendo o mais massivo o seguro social, conduzido pelas Obras Sociales, as quais, por sua vez, são de quatro tipos: as de abrangência nacional, as provinciais, as das Forças Armadas e da Segurança e as de Universidades, Poder Legislativo e Poder Judiciário (SUAREZ BALDO, 2019). O subsetor público é constituído pelos níveis nacional, provincial e municipal, com regulamentos específicos em suas 
jurisdições. Por fim, o subsetor privado possui o formato de seguro voluntário e é integrado por profissionais e estabelecimentos de saúde que atendem demandas individuais, de empresas, seguros privados e empresas de medicina pré-paga (BELLÓ; BECERRIL-MONTEKIO, 2011). O sistema de saúde argentino é, portanto, estratificado e desarticulado, mas todas as pessoas têm acesso pelo menos à cobertura do setor público, ainda que de modo desigual. Essa segmentação exigiu esforços do governo federal para coordenar as respostas à pandemia. Contudo, se verificaram atrasos na notificação de óbitos que dificultaram o acompanhamento em tempo real da evolução da doença.

Também o sistema de saúde mexicano é marcado pela forte presença do modelo de seguro social contributivo, a que tem direito apenas os trabalhadores formais e seus dependentes, de acordo com o segmento laboral a que estão vinculados. Integram esse sistema o Instituto Mexicano de Seguridade Social (IMSS), o maior em número de filiados dentre os institutos de seguro contributivo e se dirige aos trabalhadores formais da iniciativa privada; o Instituto de Seguridade e Serviços Sociais dos Trabalhadores do Estado (ISSSTE), para servidores públicos; o Instituto de Seguridade Social para afiliados à Marinha mexicana (SEMAR) e para os demais militares o SEDENA; e PEMEX, para os trabalhadores da empresa nacional petroleira. Desse modo, a oferta de serviços de saúde é altamente segmentada e a qualidade e a cobertura bastante diferenciadas. Para as famílias sem o seguro social contributivo, a opção até o final de 2019 era o Seguro Popular, que absorvia as famílias beneficiárias de transferência de renda, sem exigência de coparticipação, e as demais famílias a partir de inscrição e contribuição. A partir $1^{\circ}$ de janeiro de 2020, foi instituído o Instituto de Salud para el Bienestar (INSABI), dirigido a todos os que não contam com seguro social. Com o novo Instituto, não há necessidade de trâmites de afiliação e a cobertura nos níveis primário e secundário de saúde, incluindo medicamentos, é gratuita. Quanto ao nível terciário, podem ser cobradas cotas, de acordo com as condições das famílias e serviços prestados. O INSABI atua por meio de unidades próprias da Secretaria de Saúde do México e das unidades de saúde dos entes federativos que foram aderindo ao Instituto (MÉXICO, 2020c). Para além da estratificação do sistema de saúde, Puga (2020) destaca críticas em relação à sua demora na organização para enfrentar a pandemia, sobretudo em termos de equipamentos, logística e treinamentos de pessoal, e aponta a existência de condutas diversas entre o governo federal e os estaduais, que geraram insegurança e insatisfação da população. Ressalta-se que o governo mexicano mantém sua conduta de ampla divulgação de informação através mídia eletrônica, e disponibiliza canais de comunicação nacionais e estaduais para orientações e emergências em casos suspeitos ou confirmados de COVID-19 para a população, além de assegurar ampla gama de normatização e protocolos técnicos para profissionais de saúde (MÉXICO, 2020h).

No Brasil, a criação do Sistema Único de Saúde (SUS) desde o final dos anos 1980 universalizou a atenção à saúde no país e viabilizou significativa capilaridade dos serviços em todo 0 
território nacional. Segundo o IBGE, em 2019 mais de 70\% da população brasileira dependia exclusivamente do SUS, percentual esse que pode ter se ampliado durante a pandemia, frente ao aumento do desemprego e dificuldades de muitos trabalhadores para arcar com os custos de planos de saúde. O SUS também promoveu importante articulação entre os três níveis de governo na gestão, provisão e financiamento das ações. Esses aspectos têm sido fundamentais para o combate da pandemia, embora com diferenças significativas entre as regiões do país e a despeito da falta de coordenação por parte do governo central. Um problema enfrentado pelo SUS é seu histórico subfinanciamento, aprofundado com a EC n 95/2016 que gerou, até 2019, a perda de recursos de quase trinta bilhões de reais para o sistema de saúde. Mesmo nesse contexto, o Conselho Nacional de Saúde denunciou que até julho de $2020,70 \%$ dos recursos da saúde ainda não haviam sido aplicados. Outro entrave estrutural ao SUS é a presença de um robusto mercado de seguros privados de saúde, entrelaçado com o setor público, e com ele disputando recursos e clientelas, o que acaba por reforçar a segmentação e as desigualdades sociais.

Frente à segunda onda da pandemia na Europa e ao aumento do número de casos e óbitos na América Latina, crescem as expectativas em relação às alternativas de vacinação. Os progressos nas pesquisas e na produção de vacinas apontam para sua iminente distribuição. México e Argentina já anunciaram a aprovação e compra de vacina contra a COVID-19, a partir de Planos Nacionais de Vacinação, sendo o México o primeiro país da região a anunciar a compra para uso emergencial. No Brasil, no entanto, o presidente tem protagonizado questionamentos quanto à origem, eficácia, obrigatoriedade e responsabilidade da vacinação, transformando-a em disputa política e levando a intervenções do Legislativo e do Judiciário em defesa da imunização e cobrança da apresentação de um Plano Nacional.

\section{POLÍTICA SOCIAL EM TEMPOS DE COVID-19: AS RESPOSTAS GOVERNAMENTAIS PARA PROVISÃO DA PROTEÇÃO SOCIAL}

Conforme destacado, quando os primeiros casos de COVID-19 foram registrados no Brasil, no México e na Argentina, esses países já apresentavam indicadores socioeconômicos preocupantes. Diante da necessidade de restringir a atividade econômica para desacelerar o contágio, seus governos implementaram medidas de proteção social visando à contenção do desemprego e da perda da renda das famílias, sobretudo das inseridas na informalidade.

Para deter a falência de empresas e demissões, no Brasil foi aprovada a Lei $n^{\circ} 14.020 /$ 2020 que autoriza redução de jornada e salários e cessação temporária dos contratos de trabalho. De acordo com Ministério da Economia, mais de 15 milhões de trabalhadores tiveram contrato alterado a 
partir dessa lei. Também foram concedidos créditos e auxílios a empresas e renegociação de dívidas. No México, foram implementados apoios financeiros a microempresas e trabalhadores independentes, em modalidades de empréstimos em condições facilitadas de 25 mil pesos mexicanos (aproximadamente 6.360 reais), além de outros já existentes. Também foi criada a plataforma virtual Mercado Solidário, para divulgação da produção de artesãos, pequenos produtores, comerciantes e prestadores de serviços. Alguns programas sociais já vigentes tiveram mudanças de operação como forma de enfrentamento à pandemia, como o Bienestar de las Personas com Discapacidade o Pensión para elBienestar de los Adultos Mayores, que são pagos a cada 2 meses e foram adiantados. Uma relevante medida de apoio às empresas na Argentina foi o programa de Assistência de Emergência ao Trabalho e à Produção (ATP), que consistiu no pagamento de $50 \%$ dos salários do setor privado pelo Estado nacional, redução de até $95 \%$ das contribuições patronais ao sistema previdenciário e financiamentos mais baratos com facilidades nos prazos. Proibiram-se as demissões sem causa, as suspensões unilaterais e foram outorgados pagamentos extras para trabalhadores da saúde, da segurança e do ensino fundamental e médio.

Tanto no Brasil quanto na Argentina foram implementados auxílios monetários emergenciais. No Brasil, a transferência teve como público-alvo beneficiários do Programa Bolsa Família (PBF) e outros inscritos no Cadastro Único dos Programas Sociais do Governo Federal, trabalhadores informais, microempreendedores individuais (MEI) e contribuintes facultativos. Dados do IBGE demonstram que $49,5 \%$ da população brasileira recebeu o auxílio, alcançando $80 \%$ dos domicílios mais pobres do país e se configurando como única renda para 4,4 milhões de domicílios (IPEA, 2020). Devido aos valores, o benefício foi responsável pela saída momentânea de $20,7 \%$ da população da extrema pobreza, reduzindo-a ao menor nível em 40 anos. Na segunda edição especial sobre COVID-19 do boletim "Desigualdade nas Metrópoles" consta que os auxílios (não só o federal, mas também alguns estaduais e municipais) evitaram que cerca de $28 \%$ da população das regiões metropolitanas, ou 23 milhões de brasileiros, caíssem na pobreza durante a pandemia e contribuíram para a redução da parcela mais pobre da população nas regiões metropolitanas de $3,2 \%$, passando de 19,1\% no final de 2019 a 15,9\% em agosto de 2020 (SALATA; RIBEIRO, 2020b).

$\mathrm{Na}$ Argentina, o Ingreso Familiar de Emergencia (IFE) no valor de cerca 730 reais mensais, atendeu 8,7 milhões de pessoas, incluindo trabalhadores informais, trabalhadores autônomos de baixa renda, empregadas domésticas e beneficiários da AUH (CHENA; ROIG, 2020). Para beneficiários da $\mathrm{AUH}$ e aposentados houve também gratificações, cartão alimentação e entrega de cestas de alimentos. Outras medidas de preservação da renda das famílias foram a fixação dos valores de aluguéis e hipotecas; prorrogação de suas vigências e proibição de despejos; 0 impedimento de suspensão de serviços públicos por inadimplência (água, gás, eletricidade); a declaração da internet, 
telefonia celular e TV a cabo como serviços públicos e o estabelecimento de uma tarifa social básica para estes três serviços. Recentemente foi aprovado um imposto extraordinário às grandes fortunas pessoais, com caráter emergencial e ser pago uma única vez, para combate da COVID-19. A medida atingirá entre 10 e 12 mil contribuintes $(0,02 \%$ da população), que possuem fortunas pessoais superiores a 200 milhões de pesos (aproximadamente 12,2 milhões de reais). Estima-se arrecadar entre 300 e 420 bilhões de pesos (entre 18,3 e 25,7 bilhões de reais) (GIARDINELLI, 2020; ÁMBITO, 2020a; BBC, 2020) destinados à compra e/ou elaboração de insumos para a saúde; subsídios a empresas de pequeno e mediano porte; financiamento de bolsas educativas do Programa Progresar; ao Fundo de Integração Sócio Urbana (FISU), que visa a melhoria da saúde e das condições de moradia dos habitantes de bairros populares, e a projetos de exploração, desenvolvimento e produção de gás natural (ÁMBITO, 2020a).

No México foram aprovadas reformas na Lei Federal do Trabalho para regularizar o home office e outras formas de trabalho à distância, determinando que os empregadores assumam os custos do trabalho em casa, incluindo serviços de internet e energia elétrica e a entrega e manutenção dos equipamentos necessários para o teletrabalho (computadores, cadeiras, impressoras). Estabelece que devem ser respeitados os horários de trabalho e descanso dos empregados, informações pessoais e 0 direito à privacidade. Dados da Universidade Nacional Autônoma de México (Unam) apontam que cerca de $70 \%$ do trabalho no país durante a pandemia tem sido realizado na modalidade home office (OPERA MUNDI, 2020).

As medidas implementadas nos três países não foram suficientes para impedir a piora da situação socioeconômica. Cerca de 9 milhões de brasileiros perderam o emprego, sobretudo trabalhadores informais, levando ao recorde de $14,3 \%$ de desempregados em agosto de 2020, (IBGE, 2020). O México, por outra parte, é apontado como um dos países da América Latina mais afetados pela crise econômica em decorrência da pandemia devido ao mercado de trabalho caracterizado pela alta informalidade (que cresceu ainda mais), péssimas condições de trabalho, baixos salários e achatamento salarial. Os estados cuja economia é centrada no turismo enfrentam proporcionalmente os piores indicadores de retração e, apesar dos esforços do governo federal em efetuar investimentos para reverter esse quadro, incluindo obras de infraestrutura com potencial de geração de emprego, a condição agravada pela pandemia demanda novos e maiores investimentos, pois poderá se configurar como uma recessão profunda e duradoura (HUALDE, 2020). Na Argentina, onde o desemprego aumentou 2,7\%, chegando a 13,1\% no segundo semestre de 2020 (INDEC, 2020a), houve piora também dos índices de pobreza: na primeira metade de 2020, a pobreza cresceu 5,5\% alcançando $40,9 \%$ da população, enquanto a miséria chegou a $10,5 \%$ da população, num aumento de $2,8 \%$ (INDEC, 2020b). 
As sociedades dos três países se tornaram ainda mais desiguais no contexto da pandemia, sendo esse um determinante social da saúde. Verifica-se que o lugar na estrutura social é decisivo para o impacto da doença, a qualidade da atenção recebida e chance de sobrevivência (JUSTO, 2020). Os recortes de classe, raça/etnia e gênero estão na determinação das condições de vida na pandemia e na contaminação e mortalidade por COVID-19 (ANJOS; MAGALHÃES, 2020). No Brasil, pesquisas indicam maior prevalência de COVID-19 nos quintis de renda mais pobres e entre a população indígena, preta e parda (HALLAL et al., 2020), e aumento da desigualdade de renda nas metrópoles do país durante a pandemia (SALATA; RIBEIRO, 2020a). Embora a renda de todos os segmentos tenha caído, a dos mais pobres o fez com maior intensidade, sendo que, por fora da média, em nove do total de 22 regiões metropolitanas brasileiras os ricos ficaram mais ricos (SALATA; RIBEIRO, 2020a). Também na Argentina foi registrado aumento da desigualdade: no segundo trimestre de 2019 , os $10 \%$ mais ricos da população tinham uma renda 16 vezes superior a dos $10 \%$ mais pobres, diferença que subiu para 19 vezes em apenas um ano (INDEC, 2020c).

Por outra parte, a crise provocada pela pandemia tende a ser mais grave para as mulheres, comunidades indígenas e migrantes. No México, as mulheres encaram piores condições de trabalho, vínculos precários e baixos salários; sua participação em atividades remuneradas é a menor de América Latina; são elas as principais responsáveis pelas atividades de cuidado, que se avolumaram na pandemia, e, além disso, são vítimas da violência de gênero, fenômeno cujo aumento está documentado durante o isolamento social, em um país onde, entre as mulheres de 15 anos ou mais, 66,1\% experimentaram pelo menos um incidente de violência ao longo da vida (FERREYRA BELTRÁN, 2020). Em relação às comunidades indígenas, a incidência de pobreza, as precárias condições de vida e sua opressão histórica, as tornam mais vulneráveis aos impactos deletérios da pandemia (UNESCO, 2020). Também será necessário dar resposta aos migrantes, tanto da fronteira sul como norte do país, cujo movimento em busca de melhores condições de vida pode se acentuar no pós-pandemia (PUGA,2020).

\section{CONSIDERAÇÕES FINAIS}

A emergência da pandemia de COVID-19 na América Latina encontra um território já marcado por profundas desigualdades sociais, ainda mais agravadas pela crise estrutural do capital que se arrasta desde os anos 1970 e por um longevo e conturbado período de experimentação de medidas neoliberais, que acentuaram ainda mais as disparidades sociais na região, fragilizaram os já modestos sistemas de proteção social e aumentaram o desemprego, precarização e informalidade do mercado de trabalho, com resultados pífios ou mesmo nulos em termos de retomada de 
desenvolvimento e dinamismo econômico. A pandemia aprofunda ainda mais esse quadro e exige dos governos nacionais a implantação de políticas públicas capazes não apenas de responder de forma efetiva e oportuna às necessidades em saúde, mas também assegurar uma ampla proteção social em face das medidas de restrição econômica e de isolamento social requeridas no período.

Como aqui exposto, a adoção e abrangência das políticas sociais no enfrentamento da pandemia é afetada tanto pelo perfil dos sistemas de proteção social previamente existente quanto pela orientação política dos governos e pela dinâmica social e política de cada país. Tais aspectos são chave para a compreensão dos constrangimentos e avanços nas respostas produzidas pelo setor saúde dos países no combate à pandemia de COVID-19. Mas também as desigualdades sociais são entraves importantes no enfrentamento da pandemia. Assim, a despeito de medidas protetivas de maior ou menor abrangência e magnitude, que reforçam a proteção social existente ou introduzem novos mecanismos - todos eles temporários - a crise social própria às formações sociais latinoamericanas se agravou.

Uma questão que se coloca é quanto ao futuro da proteção social após a pandemia em um cenário de contração da atividade econômica na América Latina de 7,2\% em 2020, configurando uma recessão mais profunda do que as causadas pela crise financeira mundial de 2008-2009 e a crise da dívida da década de 1980, sendo que a economia do Brasil deve encolher $8 \%$, a do México está em via de sofrer contração de 7,5\% e a da Argentina reduziria sua atividade em 7,3\% ainda este ano (BANCO MUNDIAL, 2020).

Coloca-se, então, a necessidade ainda mais urgente de impulsionar mudanças mais profundas nos sistemas de proteção social, de modo a tornar as medidas especiais de respostas à pandemia em sistemas abrangentes de proteção social, tais como a garantia do acesso universal a serviços de saúde, a diminuição da informalidade no trabalho e a implementação de uma renda básica de cidadania de caráter universal.

\section{REFERÊNCIAS}

ÁMBITO. Punto por punto: qué establece el Aporte Solidario de las grandes fortunas. Buenos Aires, 04 dez. 2020. Disponível em: https://www.ambito.com/politica/senado/punto-punto-que-establece-elaporte-solidario-las-grandes-fortunas-n5153229. Acesso em: 4 dez 2020.

ANJOS, D; MAGALHÃES, M. Diálogo do front: pandemia e (in) capacidade governamental. Physis, Rio de Janeiro, v. 30, n.3, p. 300-303, 2020. 
ANDRENACCI, L.; FALAPPA, F.; LVOVICH, D. Acerca del Estado de bienestar en el peronismo clásico (1943-1955). In: BERTRANOU, J. et al. (comps.). En el país del no me acuerdo: (des)memoria institucional e historia de la política social en la Argentina. Buenos Aires: Prometeo, 2004.

BANCO MUNDIAL.Perspectivas Econômicas Mundiais. Disponível em:

http://pubdocs.worldbank.org/en/609221588788227652/Global-Economic-Prospects-June-2020-

Regional-Overview-LAC-PT.pdf. Acesso em: 21 dez 2020.

México. Disponível em: http://datos.bancomundial.org/pais/mexico. Acesso em: 17 jan 2015.

BARBA SOLANO, C. América Latina: regímenes de bienestar en transición durante los años noventa.

Cadernos CRH. v.20, n.50, pp.197-211.2007.

BBC. Argentina aprueba un impuesto a la riqueza para combatir los efectos del coronavirus. 05 dez. 2020. Disponível em: https://www.bbc.com/mundo/noticias-america-latina-55199876. Acesso em: 5 dez. 2020.

BBC News Brasil. A decisão do Ministério da Cidadania que põe em risco a assistência social nas cidades brasileiras. Disponível em: https://www.bbc.com/portuguese/brasil-51819528. Acesso em 19 dez. 2020.

BRASIL. MINISTÉRIO DA SAÚDE. Saúde Brasil 2018 uma análise de situação de saúde e das doenças e agravos crônicos: desafios e perspectivas. Brasília: Ministério da Saúde, 2019. Disponível em:

https://bvsms.saude.gov.br/bvs/publicacoes/saude_brasil_2018_analise_situacao_saude_doencas_agr avos_cronicos_desafios_perspectivas.pdf. Acesso em: 1 out. 2020.

BELLO, M; BECERRIL-MONTEKIO, VM. Sistema de salud de Argentina. Salud pública México, Cuernavaca, v. 53, supl. 2, p. 96-109, enero 2011.

BRODA, MA. Argentina não tem plano de recuperação. Valor Econômico, Rio de Janeiro, 16 mar 2020.

CETRÁNGOLO, O.; GRUSHKA, C. El sistema de pensiones en la Argentina. Institucionalidad, gasto público y sostenibilidad financiera. Serie Macroeconomía del Desarrollo, n. 208. Santiago: CEPAL, 2020.

CHENA, P; ROIG, A. El impacto social del IFE. Redistribuir. Página 12, Buenos Aires, 31 mai. 2020.

COBO, B; LAVINAS, L VEIGA, A. Políticas Sociais Universais e Incondicionais: há chances reais de sua adoção na América Latina? $13^{\circ}$ Congresso da Rede Mundial de Renda Básica. São Paulo: BIEN, 2010.

COLOMBO, S. Depois de explosão de casos, curva da Covid-19 recua na Argentina, e governo altera restrições. Folha de Pernambuco, 08/11/2020. Disponível em: 
https://www.folhape.com.br/noticias/depois-de-explosao-de-casos-curva-da-covid-19-recua-naargentina-e/161196/ Acesso em: 15 dez. 2020.

CONEVAL. Evaluaciones de Diseño con Trabajo de Campo a 17 programas Prioritarios de Desarrollo Social 2019-2020, 2020a. Disponível em:

https://www.coneval.org.mx/Evaluacion/IEPSM/Paginas/Evaluaciones_Diseno_Desarrollo_Social.aspx Acesso em: 18 dez. 2020.

CONEVAL. Información de la Tendencia de Laboral de la Pobreza Laboral y de la Pobreza

Laboral. 2020b. Disponível em: https://www.coneval.org.mx/Medicion/Paginas/ITLP-

IS_resultados_a_nivel_nacional.aspx. Acesso em: 20 dez. 2020.

DAMIÁN, A, La crisis internacional y su efecto en la pobreza. In: MI Patiño, DM Mendizábal y EV Lomelí (orgs.) La necesaria reconfiguración de la política social de México. León, Guanajuato: Universidad Iberoamericana León, 2011.

DONZA, E. Heterogeneidad y fragmentación del mercado de trabajo (2010-2018). Buenos Aires: Observatorio de la Deuda Social Argentina, Universidad Católica Argentina, abril de 2019. Disponível em:

http://wadmin.uca.edu.ar/public/ckeditor/Observatorio\%20Deuda\%20Social/Presentaciones/2019/2019OBSERVATORIO-DOCUMENTO-TRABAJO-HETEROGENEIDAD-FRAGMENTACION.pdf. Acesso em: 14 out. 2020.

FERREYRA BELTRÁN, MC. Desigualdades y Brechas de Género en Tiempos de Pandemia. Presentación en el Ciclo de Conferencias Las Ciencias Sociales y el Nuevo CoronaVírus. COMECSO, 2020.

FILGUEIRA, F. Modelos de desarrollo, matriz del Estado social y herramientas de las políticas sociales latinoamericanas. In: CECCHINI, S.; FILGUEIRA, F.; MARTÍNEZ, R.; ROSSEL, C. (eds.).

Instrumentos de protección social: caminos latinoamericanos hacia la universalización. Santiago: CEPAL, 2015. p. 49-84.

FLEURY, S. The Welfare State in Latin America: reform, innovation and fatigue. Cad. Saúde Pública, Rio de Janeiro, v. 33, supl. 2, 2017.

GALINDO, J; ARROYO, L. Os mapas da pandemia revelam as desigualdades na América Latina. EI País Brasil. 04 de agosto de 2020. Disponível em https://brasil.elpais.com/internacional/2020-0804/os-mapas-da-pandemia-revelam-as-desigualdades-na-america-latina.html. Acesso em: 8 de dez. 2020.

HALLAL, PC et al. SARS-CoV-2 antibody prevalence in Brazil: results from two successive nationwide serological household surveys. Lancet Global Health, 8, p. 1390-1398, 2020. Disponível em: https://www.thelancet.com/action/showPdf?pii=S2214-109X\%2820\%2930387-9. Acesso em: 28 out. 2020. 
HENRIQUES, CMP; VASCONCELOS, W. Crises dentro da crise: respostas, incertezas e desencontros no combate à pandemia da Covid-19 no Brasil. Estud. av., São Paulo, v. 34, n. 99, p. 25-44, Ago. 2020 .

HUALDE, A. La Pandemia y el Mercado de Trabajo en México: efectos graves, perspectivas inciertas. Presentación en el Ciclo de Conferencias Las Ciencias Sociales y el Nuevo CoronaVírus. COMECSO, 2020.

IBGE. Pesquisa Nacional de Amostra Domiciliar. PNAD Contínua. Segundo trimestre 2020. Principais Resultados. Rio de Janeiro: IBGE. Disponível emhttps://www.ibge.gov.br/estatisticas/sociais/populacao/9173-pesquisa-nacional-por-amostra-dedomicilios-continua-trimestral.html?edicao=28690\&t=destaques. Acesso em: 30 set. 2020.

Pesquisa de Orçamentos Familiares. POF 2017-2018: primeiros resultados. Rio de Janeiro: IBGE, 2019. Disponível em: https://biblioteca.ibge.gov.br/visualizacao/livros/liv101670.pdf. Acesso em 1 out. 2020.

INDEC. Instituto Nacional de Estadísticas y Censos. Mercado de trabajo. Tasas e indicadores socioeconómicos (EPH). Segundo trimestre de 2020. Trabajo e ingresos, v. 4, n. 5. Buenos Aires, septiembre de 2020a. Disponível em:

https://www.indec.gob.ar/uploads/informesdeprensa/mercado_trabajo_eph_2trim20929E519161.pdf. Acesso em: 19 out. 2020.

INDEC. Instituto Nacional de Estadísticas y Censos. Incidencia de la pobreza y laindigencia em 31 aglomerados urbanos. Primer semestre de 2020. Condiciones de vida, v. 4, n. 1. Buenos Aires, septiembre de 2020b. Disponível em:

https://www.indec.gob.ar/uploads/informesdeprensa/eph_pobreza_01_200703093514.pdf. Acesso em: 19 out. 2020.

INDEC. Instituto Nacional de Estadísticas y Censos. Evolución de la distribución del ingreso. Segundo trimestre de 2020. Trabajo e ingresos, v. 4, n. 6. Buenos Aires, septiembre de 2020c. Disponível em: https://www.indec.gob.ar/uploads/informesdeprensa/ingresos_2trim203E26BE94AC.pdf. -Acesso em: 19 dez. 2020.

INEGI. Instituto Nacional de Estadística, Geografía e Informática. Encuesta Telefónica de Ocupación y Empleo (ETOE), 2020. Disponível em: https://www.inegi.org.mx/investigacion/etoe/. Acesso em: 19 dez. 2020.

IPEA. Os efeitos da pandemia sobre os rendimentos do trabalho e o impacto do auxílio emergencial: os resultados dos microdados da PNAD Covid-19 de julho. Carta de conjuntura 48. Brasília: IPEA, 2020. Disponível em:

https://www.ipea.gov.br/portal/images/stories/PDFs/conjuntura/200826_cc48_resultados_pnda_julho.pd f. Acesso em: 16 out. 2020.

JACCOUD, L. Proteção social no Brasil: debates e desafios. In BRASIL. MDS. Concepção e gestão da proteção social não contributiva no Brasil. Brasília: Ministério do Desenvolvimento Social e Combate à Fome, UNESCO, 2009. 
JOHNS HOPKINS. Coronavirus Resource Center. Dados de Mortalidade disponíveis em:https://coronavirus.jhu.edu/data/mortality. Acesso em: 18 dez. 2020.

JUSTO, M. El coronavirus mata por clase social. Página 12, Buenos Aires, 26 mai. 2020.

LANZARA, AP. Capacidades estatais, trabalho e seguridade social: África do Sul, Argentina e Brasil em perspectiva comparada. Texto para discussão, n. 2052. Brasília: IPEA, maio de 2015.

LAURELL, AC. Para um novo Estado de Bem-Estar na América Latina. Revista Lua Nova, São Paulo, n. 45, p. 187-234, 1998.

LAVINAS, L. Há um clamor unanime e geral por renda básica de cidadania universal e incondicional. Entrevista ao Instituto HumanitasUnisinos. Porto Alegre: IHU On-Line, 01 de dezembro de 2018. Disponivel em:http://www.hu.unisinos.br/159-noticias/entrevistas/584990-a-garantia-do-estado-de-bemestar-social-depende-de-elevar-fortemente-a-produtividade-do-trabalho-entrevista-especial-com-lenalavinas. Acesso em: 16 out. 2020.

MÉXICO. Coordinación Nacional de Becas para elBienestar Benito Juarez. 2020a. Disponível em:https://www.gob.mx/becasbenitojuarez. Acesso em: 14 out. 2020.

MÉXICO. Secretaría de Bienestar. Programa para Bienestar de los adultos Mayores. 2020b. Disponivel em:https://www.gob.mx/bienestar/acciones-y-programas/programa-para-el-bienestar-de-laspersonas-adultas-mayores. Acesso em: 14 out. 2020.

MÉXICO. Instituto de Salud para elBienestar. 2020c. Disponível em:https://www.gob.mx/insabi. Acesso em: 14 out. 2020.

MÉXICO. Medidas Económicas. 2020d. Disponível em: https://www.gob.mx/covid19medidaseconomicas/acciones-y-programas/nueva-normalidad-244196. Acesso em: 12 out. 2020.

MÉXICO. Secretaria de Salud, Covid 19. 2020e. Disponível em: https://www.gob.mx/cms/uploads/attachment/file/600738/Comunicado_Tecnico_Diario_COVID19_2020.12.16.pdf. Acesso em: 18 dez. 2020.

MÉXICO. Covid 19 Medidas Económicas, 2020f.Disponivel em: https://www.gob.mx/covid19medidaseconomicas/acciones-y-programas/apoyos-financieros-amicroempresas-y-trabajadores-independientes. Acesso em: 29 out. 2020.

MÉXICO. Secretaria de Bienestar. Pobreza. 2020g. Disponível em: https://www.gob.mx/bienestar/documentos/informe-anual-sobre-la-situacion-de-pobreza-y-rezagosocial. Acesso em: 13 out. 2020.

MÉXICO. Secretaria de Salud. Documentos de Consulta. 2020h. Disponível em:https://coronavirus.gob.mx/personal-de-salud/documentos-de-consulta/Acesso em: 18 dez. 2020. 
OPERA MUNDI. México Aprova Lei para que Empresas paguem luz e internet de Trabalhadores em Home Office. Disponível em:https://operamundi.uol.com.br/politica-e-economia/67779/mexicoaprova-lei-para-que-empresas-paguem-luz-e-internet-de-trabalhador-em-home-officeAcesso em: 21 dez. 2020.

PRENSA LATINA. México pode tomar medidas extremas diante do aumento da Covid-19. Disponível em https://www.prensalatina.com.br/index.php?o=rn\&id=36378\&SEO=mexico-pode-tomarmedidas-extremas-diante-do-aumento-da-covid-19. Acesso em: 18 dez. 2020.

PUGA, C. Una agenda para la Pandemia. Presentación en el Ciclo de Conferencias Las Ciencias Sociales y el Nuevo CoronaVírus. COMECSO, 2020.

SALATA, A.R.; RIBEIRO, M.G. Boletim Desigualdade nas Metrópoles. Edição especial COVID-19. Porto Alegre/RS, n. 1, 2020a.

SALATA, A.R.; RIBEIRO, M.G. Boletim Desigualdade nas Metrópoles. Edição especial COVID-19. Porto Alegre/RS, n. 2, 2020b.

SANTOS, MPA. et al . População negra e Covid-19: reflexões sobre racismo e saúde. Estud. av., São Paulo, v. 34, n. 99, p. 225-244, ago. 2020.

SOUTO MAIOR, A. Desigualdad Social, Ciudadanía y Reconocimiento: discusiones desde programas de transferencia de ingresos en México y Brasil. Tese de Doutorado, Universidad de Guanajuato, 2015.

SUÁREZ BALDO, VS. Problemas associados à segmentação e fragmentação dos sistemas de saúde: uma revisão da literatura sobre o caso da Argentina. Sociedade em Debate, v. 25, n. 1, p. 73-91, 2019.

SUÁREZ BALDO, VS; MATTOS, ALC. Política de isolamento cava diferença entre os vizinhos Argentina e Brasil. Brasil de Fato, Rio de Janeiro, 04/06/2020. Disponível em:https://www.brasildefato.com.br/2020/06/04/artigo-politica-de-isolamento-cava-diferenca-entre-osvizinhos-argentina-e-brasil. Acesso em: 4 jun 2020.

UNESCO. Pueblos indígenas y Covid19: una mirada desde México. Disponível em:https://es.unesco.org/news/pueblos-indigenas-y-covid-19-mirada-mexico. Acesso em: 29 out 2020.

VALOR ECONÔMICO. Efeito Bolsonaro? Disponível em:https://valor.globo.com/opiniao/coluna/efeitobolsonaro.ghtml.Acesso em: $18 \mathrm{dez} 2020$.

YIN, R. Estudos de Caso: planejamento e métodos. $2^{\mathrm{a}}$ edição. Porto Alegre: Artmed, 2001.

ZAIAT, A. Ocho puntos de la devastación económica de Macri. Página 12, Buenos Aires, 17 nov 2019. 